\title{
Linear to Granular: Preparing Descriptions for an ArchivesSpace Migration
}

\section{By William W. Hardesty}

\begin{abstract}
This article describes and analyzes the data cleanup undertaken at Georgia State University's Special Collections and Archives (GSU) to migrate collection descriptions from Archivist's Toolkit (AT) to ArchivesSpace. Specific work described includes revising and consolidating name and subject headings stored in the AT database and reformatting AT resources (finding aids) that had been created in Encoded Archival Description to mimic an older paper inventory format. The article looks back to the earliest finding aids at GSU and traces their development along with the evolution of archival descriptive formats, identifying practices that led, even in AT, to creating finding aids with a linear structure. With the migration complete, the collection descriptions are now in ArchivesSpace, which integrates description creation, storage, and display in a single database. Having collection data and presentation in the same system will change practices, and its interface will affect user interaction with finding aids.
\end{abstract}

\section{Introduction}

Over several years, archivists at Georgia State University Special Collections and Archives (GSU) prepared for a migration from Archivists' Toolkit to ArchivesSpace. This article describes the cleanup of controlled vocabularies and finding aids undertaken for the migration. Decades' worth of GSU's finding aids-once paper inventories, then HTML web pages, later standardized as Encoded Archival Description (EAD) all now reside in one ArchivesSpace (ASpace) database and are displayed through its web interface. In addition to describing the data cleanup, the article will look backward over 40 years to the earliest finding aids at GSU and the practices they represented. The body of data corrected and reformatted to migrate into ArchivesSpace represents assumptions about user interaction with finding aids as well as the realities of working with multiple systems. In the integrated ArchivesSpace system, both user assumptions and practices are likely to change further, as description shifts from a linear, structured form to a highly searchable, granular one. Although this migration was a local project, it is part of the broader history of the profession's evolving efforts to connect users and collections and opens a small window on the issues involved in that process.

\section{Background}

The two open source systems need little introduction to archivists. Archivists' Toolkit (AT), developed with financial support from the Andrew W. Mellon Foundation, was a collaborative effort including staff at multiple repositories resulting in a database application managing accession, description, and authority data, as well as digital object metadata. AT was a backend system that output EAD and collection-level MARCXML, but 
it had no integrated public access mechanism. Another open source application, Archon, developed at the University of Illinois, provided the tools to create a web portal in addition to EAD and MARCXML output, but it had less powerful collection management capabilities. ${ }^{1}$ Archon and AT announced plans to merge into ArchivesSpace in 2009; the new platform's official release came in 2014. ASpace, institutionally housed at Lyrasis, provides both AT's database features and, like Archon, a built-in web interface to connect researchers to archival resources. In merging the programs, ASpace pledged to retain the capabilities of the predecessor systems and to make migration tools available so both user communities could adopt the new platform. In 2017, Version 2.1 integrated a major enhancement of the public user interface into the application. ${ }^{2}$

Both AT and Archon had sizable and committed groups of users, so ASpace has been an object of interest and expectations since it was announced as their replacement.

Repositories using AT or Archon had to make decisions about migration to the new platform, and other archivists have learned about ASpace to measure its suitability for their local needs and situations. The software has been a topic of countless public and private communications among archivists and numerous presentations and meeting sessions. ${ }^{3} \mathrm{At}$ the time of this writing, over 350 institutions are members of the ASpace community, and other entities may use the open source software without paying the membership fee. ${ }^{4}$ These numbers suggest that future researchers will come to find the ASpace interface a familiar portal to information about unique resources in research repositories.

\section{Literature Review}

The migration process itself has been well supported by ASpace and, in turn, well documented by archivists, both in the literature and on the World Wide Web. Not all archives migrated from one of the predecessor systems, and some institutions populated ASpace repositories by ingesting EAD XML files. Archivists at Harvard University described a large project to migrate an "enormous trove of finding aids from a homegrown backend solution to ASpace," made more complex by the fact that EAD accommodated great flexibility in implementation. ${ }^{5}$ The Bentley Historical Library at the University of Michigan also had to move thousands of XML files into its instance of the system and, like the Harvard team, attempted to automate as much of the cleanup as possible. ${ }^{6}$ Special collections at the University of Minnesota worked with Lyrasis on a hosted installation to house its thousands of EAD finding aids, which again reflected a range of practices that affected the migration. ${ }^{7}$

Other adopters of ArchivesSpace analyzed the effect on workflow and standardization that its powerful tools can have. Western Carolina University did not have a body of EAD finding aids and, having adopted ASpace, used its built-in encoding tools to create EADs systematically for the first time. ${ }^{8}$ ASpace was the first collection management system adopted at the University of Nevada-Las Vegas, and staff members described their implementation of a capability originated in the predecessor systems to create collection-level MARCXML records. ${ }^{9}$ In another postimplementation account, 
archivists at the University of Minnesota analyzed the effect ASpace's tools have had on their processing and descriptive workflow. ${ }^{10}$

Because the ASpace backend database is so similar to that of Archivists' Toolkit (although collection information in ASpace is organized into more tables than in AT), the shift in descriptive workflow and data structure can be relatively smooth for a repository migrating from AT. ${ }^{11}$ Archivists and others have made available various accounts of the technical details of an AT-to-ASpace migration in the form of blog entries and online notes. The ArchivesSpace organization worked with vendor Hudson Molonglo to create the application, and one of its developers provided guidance on technical aspects of the process. ${ }^{12}$ Yale University had the difficult task of migrating multiple AT instances into a single one of ASpace and worked with Hudson Molonglo on aspects of it. ${ }^{13}$ An archivist at Pacific University provided an account of working with local tech staff to manage a migration, and the Rockefeller Center Archive made available a detailed account of its AT cleanup, data migration, and customization of ASpace. ${ }^{14}$

\section{Institutional Context and Practices}

Special Collections and Archives at Georgia State University in Atlanta is a fairly young (started 1971) repository that has grown to reasonable size (about 20,000 linear feet of records), housing not only the GSU institutional archives but also collecting in several distinct areas, including the Southern Labor Archives, the Popular Music and Culture Collection, and the Archives for Research on Women and Gender. Descriptive documents from GSU's special collections appeared in the professional literature not long after it was founded as the Southern Labor Archives, as examples in the 1976 Society of American Archivists (SAA) committee report that provided American archivists with a "handbook of techniques" for creating finding aids and in the first manual on arrangement and description published by SAA. ${ }^{15}$ David B. Gracy II, GSU's first archivist, chaired the final iteration of the committee and authored the manual. The product of the SAA Finding Aids Committee was an effort to quantify practices and build toward a standard for archival finding aids, an enterprise comparable to the work that preceded EAD nearly 20 years later. The committee and its project informed Gracy's authorship of the manual. ${ }^{16}$

The SAA Basic Manual Series, the first manuals endorsed by the organization, has been retrospectively viewed as a significant step in the adoption of the principles of the public records tradition (as opposed to the historical manuscripts tradition) for management of manuscripts by American archivists. ${ }^{17}$ In contrast to long-established repositories with troves of collection information representing decades of practices, the finding aids and access tools at GSU were created and matured with the modern profession. Through the manual and handbook, which predated Steven L. Hensen's Archives, Personal Papers, and Manuscripts and the MARC Format for Archival and Manuscripts Control (MARC AMC) by several years ${ }^{18}$ GSU's finding aids can be symbolically traced back to the beginnings of the standardization of American archivists' descriptive practice. The documents can be traced back genetically too: some of the data in the current ASpace instance was created under Gracy's purview. 
In the area of names of individuals and organizations, archivists' descriptive standards and tools have evolved dramatically since the early 1970s. In one example, an early inventory sheet from GSU shows an organization called "Asheville Carpenters Union 384," the name by which the group of building trade workers in North Carolina was known (see Figure 1). The 1976 inventory also indicates date and geographic coverage. The main access tools in the reading room at that time were catalog cards and index entries based on inventories. ${ }^{19}$ From 1973 on, GSU contributed to The National Union Catalog of Manuscript Collections (NUCMC), establishing some names that entered the Library of Congress (LC) authorities, although only a few score of hundreds of GSU collections made it into NUCMC. By the 1980s, with the MARC AMC standard, name authority control and archival holdings could be linked on an ongoing basis. Like many other American archives, GSU joined a networked world with the entry of records into the Research Libraries Information Network (RLIN). The Asheville Carpenters records were not described in NUCMC, but the name was standardized in a statewide cataloging project in the late 1990s, when the LC form of the name was established on an RLIN record and LC subject headings assigned to the collection. ${ }^{20}$

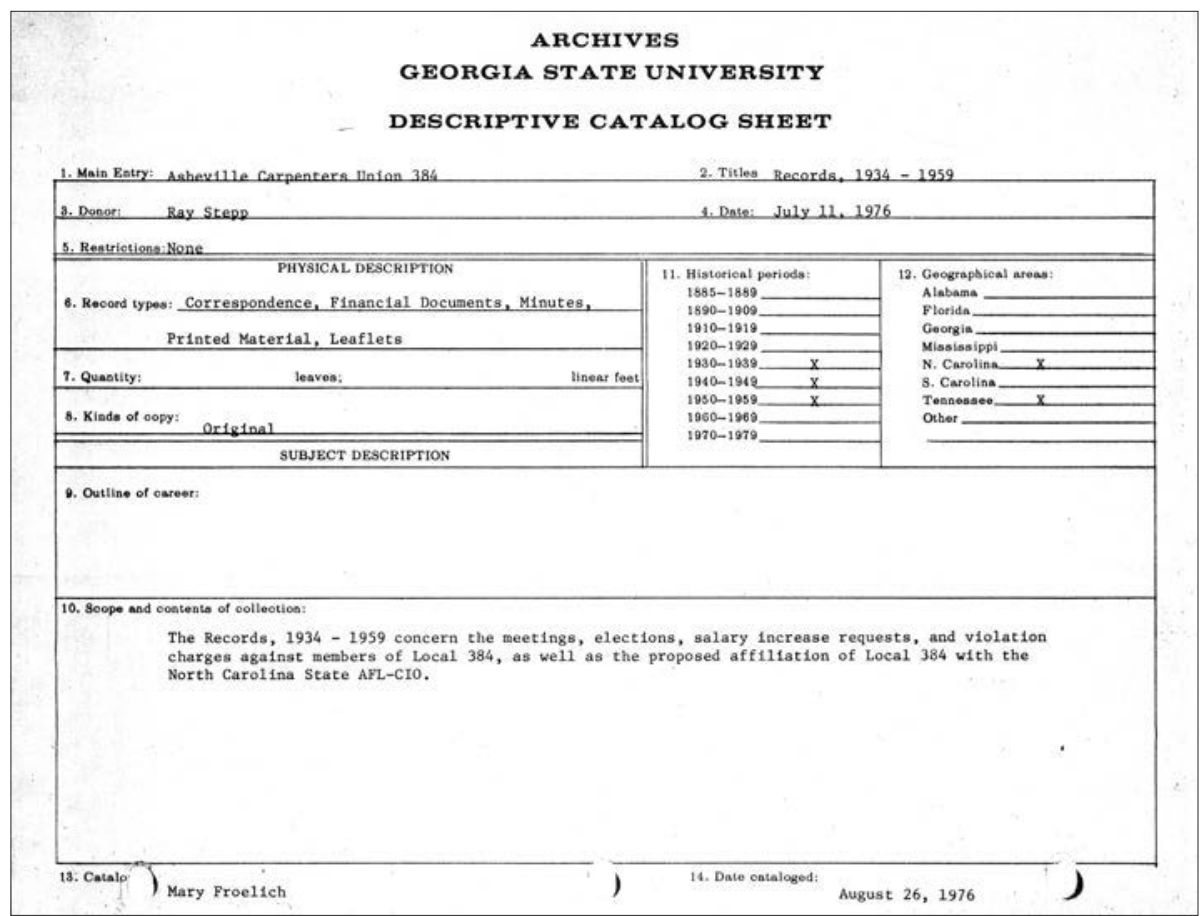

Figure 1: Original descriptive worksheet for the Asheville Carpenters records (1976), including the scope-and-contents note and temporal and geographic access points

The established name, "United Brotherhood of Carpenters and Joiners of America. Local 384 (Asheville, N.C.)," and other access points created by the catalogers made it 
into the local online public access catalog and OCLC's WorldCat by the early 2000s. However, the noncontrolled form of the name was on the GSU website by that time: the paper inventory had been encoded in HTML and published (see Figure 2). Unlike librarians working in a system with necessarily strict authority control, archivists - at GSU and elsewhere-had to negotiate among representations of their collections on paper inventories, old catalog entry cards, local MARC records, networked MARC records, web pages, and EAD files at this time. In addition to translating among those siloed information systems, work also had to be coordinated between processors, archivists, professional catalogers, and HTML-fluent encoders of web pages.

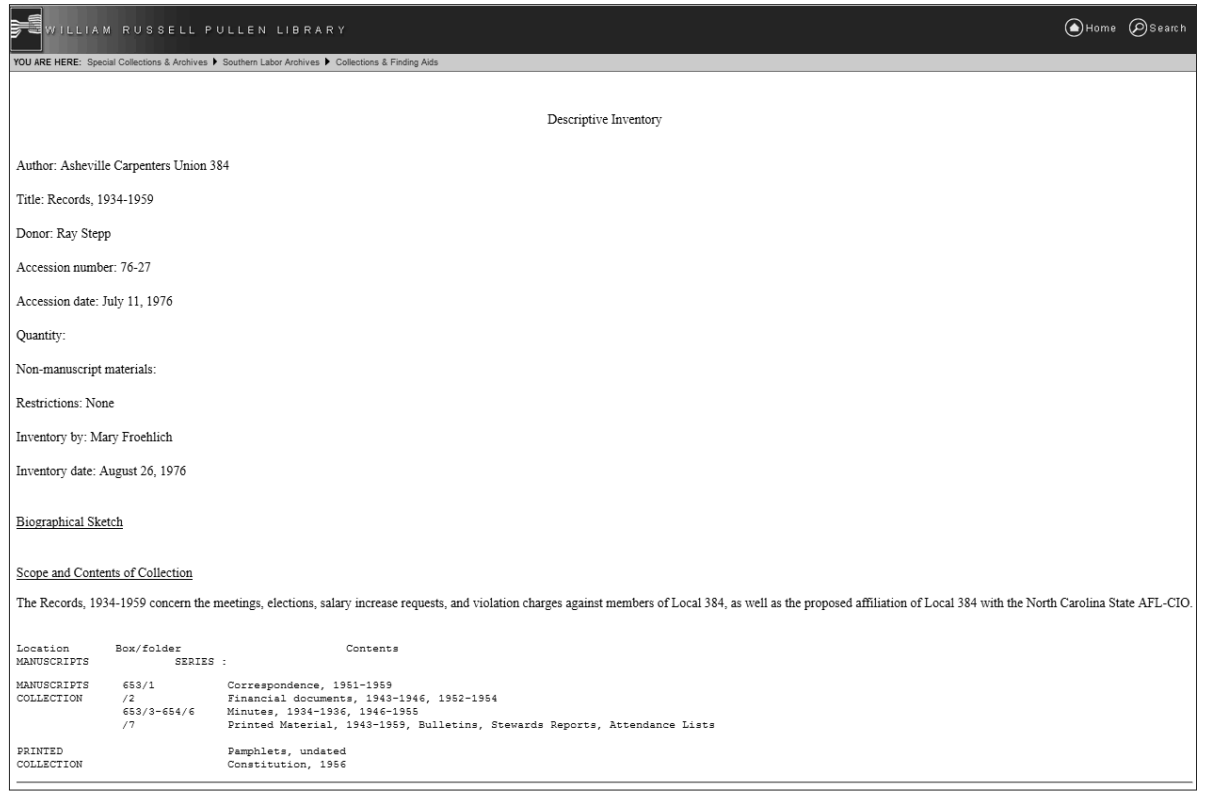

Figure 2: The descriptive inventory rendered as an HTML web page (2001), diverging by this time from the catalog record created for RLIN and missing the added access points from the paper inventory. From the Internet Archive Wayback Machine's crawl of GSU's (then) Pullen Library, July 24, 2001, https:/l web.archive.org/web/20010724140238/http://www.library.gsu.edu:80/spcoll/Collections/ Labor/76-27.htm

From its founding, the department separated "special record material," such as photographs, audiovisual records, and printed matter, from the collections. Access to them was through indexes and another card catalog, and collection inventories listed the separations that had been made after the container list. ${ }^{21}$ The small collection from the Asheville Carpenters included such items (see Figure 3). For a researcher in the reading room, this helpful system provided not only a full account of what was received from the carpenters on the inventory, but also clear cues about how to access it. Indeed, this linear format seemed so logical that, as it had been on the HTML web page, it was later perpetuated in EAD, in defiance of the correct use of the description of subordinate components. 
Main Entry: Asheville Carpenters' Union 384

Title: Reocrds, 1934 - 1959

Source: Ray Stepp

Date: Ju1y 11, 1976 Accession Number: $\quad 76-27$

Restrictions: None

Quantity: leaves, items, linear feet

Inventoried by: Mary Froehlich Date: August 26, 1976

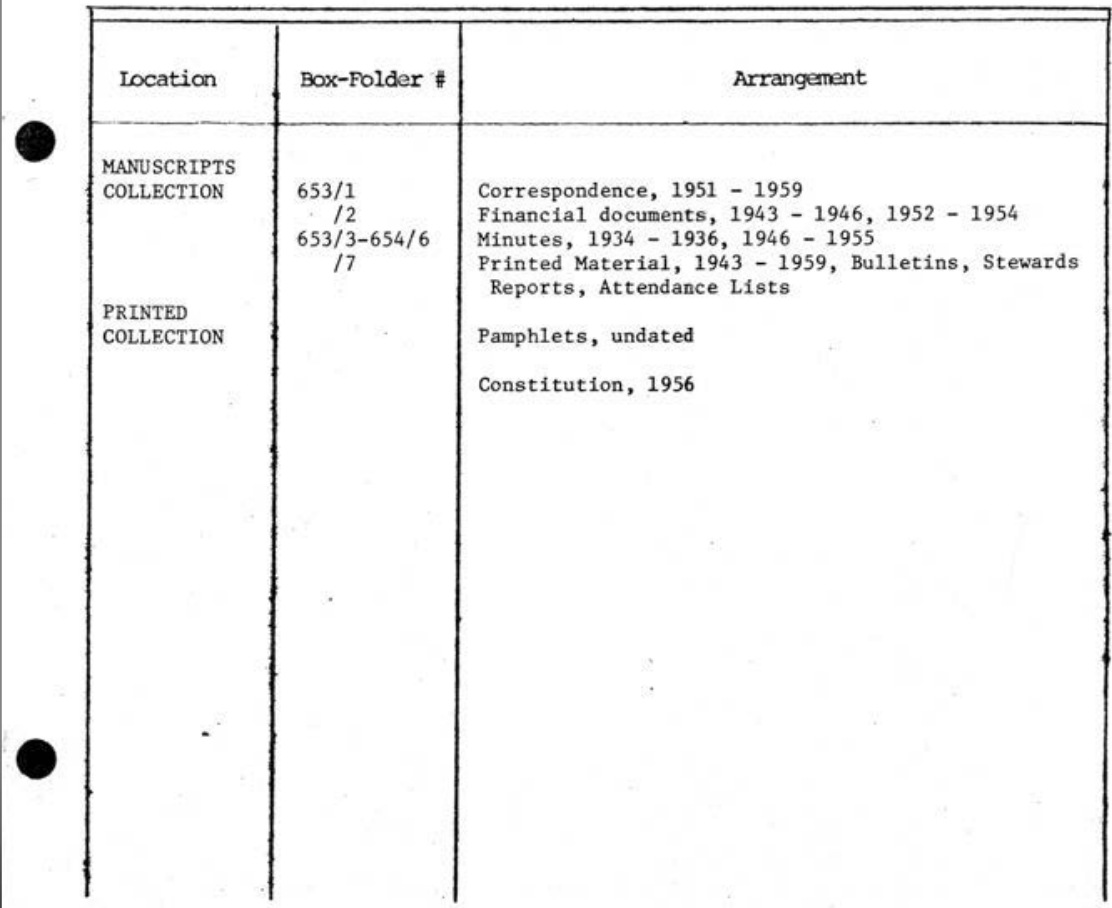

Figure 3: Original inventory (1976) showing the contents of the Asheville Carpenters collection as well as separated materials. A different early container list from GSU was reproduced both in SAA's Inventories and Registers: A Handbook of Techniques and Examples and in its Basic Manual series publication, Archives \& Manuscripts: Arrangement and Description

In encoding web pages and later EAD, GSU was in a reasonably advantageous position because of the relative modernity of its finding aids, all of which were clear in 
organization and followed a standard inventory format. The EAD finding aid for the Asheville Carpenters records, created in 2006, was understood to be an authoritative document that combined the original descriptive work of the processor, the authority and access point work that had formerly only been in library catalogs (RLIN, OCLC, and local), and also information recommended by Describing Archives: A Content Standard (DACS) that the old HTML finding aid and catalog record lacked. GSU implemented AT for accessions information in 2009 and ingested its existing EAD, moving to AT for finding aid creation, in 2012. The Asheville Carpenters finding aid was part of the data that would be migrated to ASpace.

\section{Migration Preparation \\ Controlled Vocabulary}

With release of ArchivesSpace imminent in 2014, GSU began to prepare for eventual migration, undertaking data cleanup well before a migration date had been designated. The process was projected over three years, built into the department's goals by the head of the processing unit. ${ }^{22}$ Rather than taking on the cleanup as a special project, it was planned as a part-time task while regular processing and descriptive work continued. The first step was tied to initiatives in the library's Technical Services and Digital Library Services Departments. All three departments reached a consensus that, for digital projects, GSU would adapt FAST (Faceted Application of Subject Terminology), OCLC's controlled subject vocabulary designed for use by noncatalogers. Because Special Collections relies on student, intern, and volunteer help for processing and description, the straightforward system, and the efficiency it created, appealed for finding aids as well. Furthermore, the EADs were uploaded to the same CONTENTdm instance as the library's digital objects. AT's native tools made it a relatively simple task to collapse together subject terms with various geographic and date subfields into a single FAST term, resulting in a more concise and robust vocabulary to describe collections, as well as one that linked collection descriptions to digitized content.

With the subject vocabulary streamlined, GSU turned to the name table in AT. The body of names as a whole was confusing and occasionally contradictory. Processors exercised discretion in selecting access points and created them differently at different times. Some, like the Asheville Carpenters, had been established by professional catalogers for adding terms to both the local integrated library system and OCLC's WorldCat, but variations persisted. Generally, no effort had been made for authority control of the names associated with donors and unprocessed collections. The latter were separated from the process, and the other names were assessed for their suitability in what was assumed would eventually be an environment in which GSU's archival data could be shared. Name forms of organizational record creators were verified and personal names were disambiguated when necessary. In some instances, old problems were addressed: for example, different forms of an individual's name might appear on oral history and collection records, if processed at different times. Although the vocabulary consisted of over 3,000 names, by limiting scope to the set that would appear on finding aids ("resource records" in AT and ASpace terminology), working with the library's 
professional cataloging staff to define guidelines, and, crucially, using AT's native tools (also in ASpace) to encode the revised terms - specifying both thesaurus and cataloging rules, which were invaluable to track progress - the task was manageable. Following the controlled vocabulary cleanup, with the subject and name lists in AT improved, attention turned to the finding aids themselves.

\section{Finding Aid Formatting and Structure}

The second year of preparation was slated for assessing and planning editing of the resource records. GSU had around 600 EADs in AT at the time of migration and another 900 resource records in the system that were empty top-level descriptions generated from accession records. This corpus of encoded finding aids had been built up over more than 15 years. Inevitably, with many hands involved, a large quantity of legacy data, and local practices (and standards) evolving, variations were introduced in date format, capitalization and punctuation, and extent information. With only 600 full EAD finding aids, it was possible to open each and do minor editing of the collection-level description (or the "Basic Description" in AT) to fix these variations, which made the top-level data about each collection look the same, a nicety on individual HTML finding aids but a potential source of confusion in a database environment. It was not feasible at this point to revise content in AT's notes and container lists for the collections. ${ }^{23}$

More challenging were effects of previous EAD encoding practices at GSU. These deliberate choices had been made because of the nature of the legacy data and assumptions about the finding aids as documents. The earliest vendor-created EADs were encoded from paper copies of finding aids and inventories notated with markup guidelines. The form of the finding aid was replicated in EAD, and those practices were carried into new encoded files and templates so all the online finding aids matched. Practices mimicking the paper documents in electronic format fell into two areas, stylistic and structural. The stylistic decisions were often in lieu of stylesheet customization, which GSU had never undertaken. ${ }^{24}$ Choices to employ emphasis tags, for instance, served to create visual markers that would have properly been kept out of the EAD data. One structural practice was intended to create a stylistic result. Some short finding aids that were simple lists, all at the same component level, had been nested in a < $01>$ wrapper that did not represent an organizational level but was inserted to provide a heading for the inventory. Without it, the stylesheet in use would not have rendered the list information correctly, so this created a readable HTML finding aid but also falsely nested an inventory within a dummy level. If viewed as an EAD structure tree in ASpace, the result would be confusing and unnecessary as well as an incorrect application of the standard. Unlike the extra emphasis tagging, this encoding practice was corrected on the AT records prior to migration.

Other liberties with the structure of EAD had been taken to replicate specific features of GSU's old finding aids. Many contained appendixes of separated materials, some very detailed and running to pages in their original typed paper form. The Asheville Carpenters records example is a very straightforward one. Moving these various lists to the correct elements of the collection-level description of the EAD file (or, in AT, the 
correct notes fields) was necessary to allow ASpace to yield unambiguous search results. Because the lists needed to be re-encoded to move to the correct AT field, this task was time consuming, but it resulted in much cleaner data for the migration. The final year of planned preparation was intended for finishing the finding aid cleanup and, based on that experience, assessing local practices for ongoing finding aid creation. The year brought no major surprises, and the head of processing used the accumulated experience to revise data-entry guidelines for finding aids so GSU could migrate into ASpace with both cleaned data and revised practices for the new system.

\section{Text Changes in the Database}

With the vocabulary cleaned up and finished, the finding aids assessed, elements moved and regularized, and new data-entry guidelines in place, the AT-to-ASpace migration moved toward its technical phase. GSU Library's Digital Library Service personnel undertook the actual work of installing the software and migrating existing data. The process offered the opportunity to address some cleanup more efficiently accomplished in the database than through either the AT or ASpace interface. Some of this was simple inconsistency. For example, the stacks locations tables had not had coordinate names entered identically for different storage sites, a matter easily resolved with a global text change of the AT database on the server. Another inconsistency apparently was created on ingest of legacy EAD into Archivists' Toolkit. One whole element in the profile description, language-never rendered in GSU's HTML versions of EAD but exposed in the ASpace public interface-had been ingested as the content of the field in AT, so code appeared in the public view. ${ }^{25}$ Another text change solved the problem.

In a third instance, once again, decisions to create a digital representation of the old paper finding aids and to style them in EAD data, not through a stylesheet, had had effects. What had been listed on the original typed finding aid as "Minutes, 1950 " was rendered into the converted EAD with an added comma and space, as “<unittitle>Minutes, </unittitle > < unitdate $>1950<$ /unitdate $>$," a practice that continued on newly encoded finding aids and even in AT. Rather than employing a stylesheet to avoid a display of "Minutes1950," consistent, pleasingly readable web finding aids were created at the cost of EADs with unnecessary characters on virtually every line of their descriptions of subordinate components. The current version of ASpace has a stylesheet for the public interface that adds the comma, so, as encoded, the data would yield a display of "Minutes, , 1950" in the new system. This too was a simple text change on the server. What were once several hundred EAD files moved one step closer to being a single, standardized set of data. The migration was seamlessly made at the end of 2017, over three years after processing staff had started preparation work.

\section{Implications of the Migration}

\section{Names}

In ArchivesSpace, archivists have something like their own integrated library system, a single platform that allows creation, storage, manipulation, and also display of information about collections from accessioning to completed processing. Although its name 
control capabilities were impressive, Archivists' Toolkit did not have the display mechanism of Archon and therefore could not provide this vertical integration. AT was not web based, either, and ArchivesSpace has the ability to search for and import LC Name Authority File information. Compared with the practices at GSU in the 1970s, state of the art for American archivists then, the systems of the early EAD era a quarter of a century later were astonishingly standardized and connected across the profession. Still, as the AT data exposed retrospectively, the systems were siloed, as were the skill sets of the processors and catalogers who worked on descriptions. Moving forward, GSU is instituting new workflows to establish names in the local ASpace installation at the point of accessioning. Without requiring further intervention, names will travel through processing workflow to public presentation in the interface and be exported for catalog records. Of course, the next horizon, in which sharable names and historical sketches are disassociated from finding aids, is visible in ISAAR(CPF) and Encoded Archival Context for Corporate Bodies, Persons, and Families (EAC-CPF), and in ASpace's structuring of information. ${ }^{26}$

\section{Finding Aids and Linearity}

For an institution like GSU that did not utilize a dedicated platform for finding aidssuch as Archon provided, or DLXS, or various consortium-based projects-EAD files equated to web pages. ${ }^{27}$ The EAD finding aid was so structured and self-contained that, even when uploaded into GSU's instance of CONTENTdm, it was easily conflated with its presentation. Furthermore, even though AT was an impressively constructed database to store archival information, as far as public presentation it was, for GSU's purposes, an EAD encoding tool. ${ }^{28}$ In its final pre-ASpace form, the Asheville Carpenters finding aid was published as a DACS-compliant EAD finding aid that rendered the inventory into a small part of the whole document (see Figure 4). Archivists speak of "reading" finding aids, and many of the corrections made leading up to the migration, such as the extra commas and unnecessary headings, had been introduced originally to enhance readability online or of printed documents. The addition of the separated materials, by definition no longer in the collection, into the description of the collection's components in EAD was a deliberate attempt to create a structured document with a logical beginning, middle, and end.

While a linear, paper finding aid was the best available tool when GSU began creating access to its collections - indeed, with the work of the Finding Aids Committee and the Basic Manuals, the finding aid and inventory were then reaching their modern form - the format has been found lacking in recent years, criticized for being created and perpetuated in new formats without analysis of user needs, for not communicating decisions that shaped the body of records, and for trapping collections in time-bound, hard-to-update descriptions, as well as for concealing decisions made about a given group of materials behind an omniscient voice. ${ }^{29}$ Sharon Thibodeau has speculated that EAD might have prolonged the use of detailed inventories in the profession and that future "information seekers [may be] unwilling or unable to navigate within the hierarchy of an inventory in order to benefit from its guidance." 30 

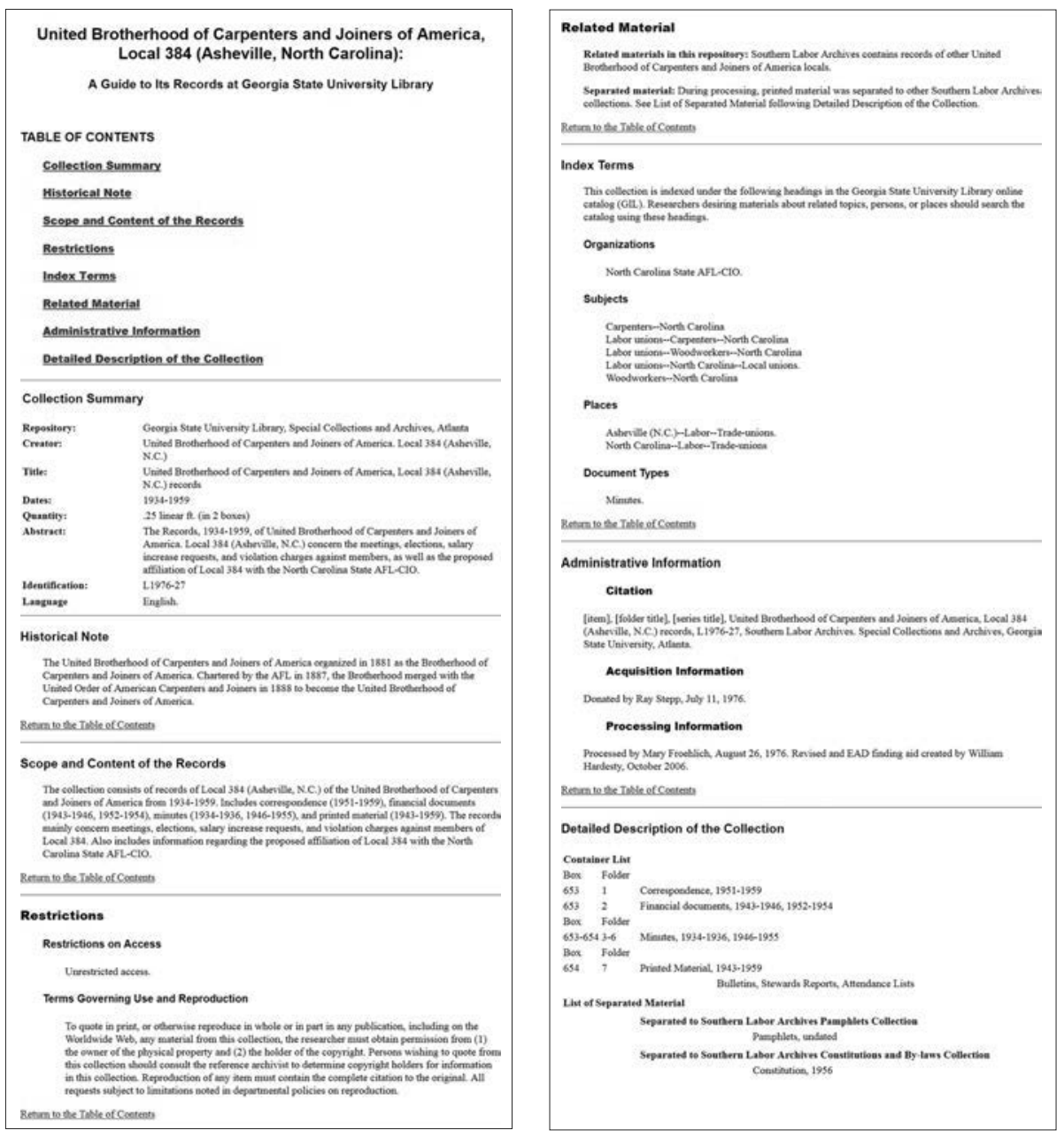

Figure 4: Encoded Archival Description finding aid for the accession (2006), compiling the original description and inventory, the access points created almost a decade earlier for a MARC record, and further descriptive elements as defined by DACS into a single document (of which, in this instance, the inventory is a small part)

\section{Searching and Granularity}

GSU encoded its first EAD in 2001, and the standard has been integral to the growth of the department's web-based collection information. However, almost a decade ago, Elizabeth H. Dow suggested that EAD might be a "halfway technology" developed to answer "the wrong question": using technology to disseminate finding aids as opposed to "connect[ing] researchers to archival materials." How well EAD serves the latter goal is a question archivists have grappled with for years. ${ }^{31} \mathrm{With}$ its integrated display, ASpace now means that finding aid information can be entered by staff and accessed by users without ever being assembled as an EAD file. Nevertheless, the structure 
provided by the standard is integral to ASpace, as it was to AT and Archon. With the EAC-CPF standard now making it possible to encode contextual entities and functions, EAD's "underlying technology and semantics and structure," as Daniel Pitti has pointed out, ". . . provide a strong base for transforming archival description." ${ }^{2}$

Before ASpace was implemented at GSU, a keyword search in the library's

CONTENTdm, for instance (or, earlier, on its website), might yield a finding aid, which would require another text search to locate the desired term, exactly like interacting with a web page in a browser. ASpace answers researcher queries in a direct way familiar to any user of the contemporary web: as database results ${ }^{33}$ (see Figure 5). Where EAD web pages, when searched, yielded results that had to be interpreted based on their context in the hierarchical document, an ASpace keyword search provides a range of results, from controlled vocabulary terms to collection titles to "archival objects," or descriptive components within collection resource records. Furthermore, the results can include components of many different collections, something never possible in GSU's web page-based displays. The system's default is to display the scope-and-contents note of those objects, or the one from the nearest level above, giving researchers accustomed to archival practice a good impression of what their search yielded. As part of GSU's revision of its descriptive guidelines postimplementation, it is breaking up longer scope notes on collections organized to multiple levels. In the web page-based presentation format, the assumption was that the collection-level descriptions might be consulted, but that lower-level descriptions in a long finding aid might be overlooked, especially when a researcher was seeking keywords. Moving description to lower levels in ASpace where appropriate and possible will serve users better.

In the default ASpace display, the collection hierarchy is always visible for further orientation and navigation. The inventory display permits a user to toggle between intellectual and physical arrangement. The old separation lists, acceptable on the inventory and even EAD web pages, cannot be perpetuated in the ASpace environment. In their original form, the lists communicated that, in this example, a union constitution from 1956 had been received with the collection, was moved to a different collection for access and preservation, and could be accessed through another descriptive resource. Researchers could go to the constitution using the manuscript collection's inventory, or through the card catalog if they had a less specific research topic than the Asheville Carpenters. The linear format of the finding aid was intended to make this clear, and even the EAD version, although deliberately miscoded, could present these lists as back matter to the descriptive document. The constitution could not stay in the ASpace resource hierarchy; its new parent collection and physical housing information reside elsewhere in the ASpace system. When description is reduced to a database record, collection information has to be unambiguous and contextual cues cannot be relied upon. This clarity should improve and sharpen practice. Missteps like those the migration exposed-such as ignoring the data standard to present the separations in a familiar manner, allowing variant versions of terms to be introduced across systems, and adding extra characters into fields for the sake of presentation on another platform-will be easier to avoid with ASpace's integrated display. 


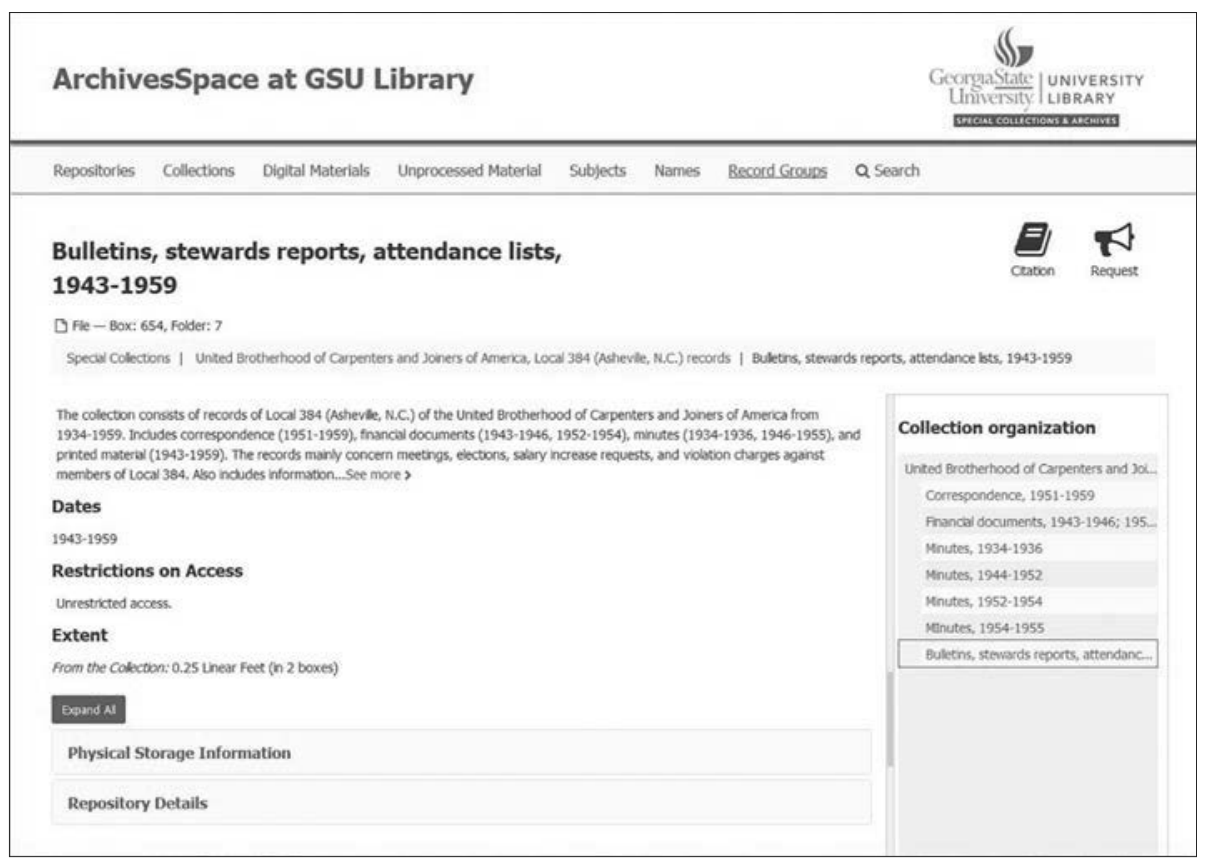

Figure 5: The ArchivesSpace public interface presentation of a file-level record from the Asheville Carpenters materials (2018). The full collection tree is to the right, and the default presentation pulls the scope-andcontents note relevant to the file's level in the hierarchy (collection level in this example) into the display.

\section{Conclusion}

In 1965, in The Management of Archives, a key text in the spread of public archives concepts to manuscript repositories and an influence on the early practices at GSU, T. R. Schellenberg asserted that "Descriptive work involves an element of self-abnegation for the archivist, in that it makes available to others [the archivist's] own knowledge about documents" and, ultimately, renders the archivist "unnecessary in the use of the material." ${ }^{34}$ Tools and practices have changed. Today, archivists can present-anywhere in the world, via a system like ASpace-fuller, more standardized collection information than they could 50 years ago, and we strive to be as deliberate as possible in alerting our patrons to how we have shaped the materials they use. But Schellenberg's point stands as a practical one: the more description that goes into a collection, the less intervention is required for a researcher to find what is needed. In preparing for the migration to ArchivesSpace, GSU confronted the confused legacy of multiple descriptive standards, of the assumptions made when descriptive information moved into new control systems, and of having had description and access separated on multiple platforms. With its combination of workflow efficiency, standards compliance, and an integrated public interface-which provides such clean and granular results that the architecture of archival description can be rendered invisible to a user who chooses not to see it-ArchivesSpace points toward enhancing access to collection content by increasing user control over the descriptive form of archivists" "knowledge about documents." 


\section{ABOUT THE AUTHOR}

William W. Hardesty is the coordinator of archival collections management in Georgia State University Library's Special Collections and Archives. He earned an MLIS from the University of Texas at Austin and an MA in history from Miami University. His research interests include arrangement and description, photographic collections, and the history of archival practices.

\section{NOTES}

1. See http://www.archiviststoolkit.org, and Bradley D. Westbrook et al., "The Archivists' Toolkit: Another Step toward Streamlined Archival Processing," Journal of Archival Organization 4, nos. 1-2 (2007): 229-53, doi:10.1300/J201v04n01_12; http://archon.org, and Scott W. Schwartz et al., "Archon: A Unified Information Storage and Retrieval System for Lone Archivists, Special Collections Librarians and Curators," Partnership: The Canadian Journal of Library and Information Practice and Research 2, no. 2 (2007), https://journal.lib.uoguelph.ca/index.php/perj/article/view/246.

2. See http://archivesspace.org; for more on the history and goals of the project, see Mark Matienzo and Katherine Kott, "ArchivesSpace: A Next-Generation Archives Management System," in Museums and the Web 2013, ed. Nancy Proctor and Rich Cherry (presented at Museums and the Web Conference, Portland, OR, January 31, 2013), https://mw2013.museumsandtheweb.com/ paper/archivesspace-a-next-generation-archives-management-system. For the interface project, see https://archivesspace.atlassian.net/wiki/spaces/ADC/pages/22282254/Public+Interface+Enh ancement+Project.

3. At the 2015 Society of American Archivists Annual Meeting, some early adopters shared their ASpace experiences with an audience that knew of, but perhaps had not used, the new application in a session titled "Don't Break It on Tuesdays and Other Tales: ArchivesSpace in Practice" (Cleveland, $\mathrm{OH}$, August 22, 2015). Perhaps the rapid growth of the ASpace community is seen in the fact that, by the following year, a lightning session on customizations titled "Making ArchivesSpace Work for You" was on the program (Atlanta, GA, August 5, 2016). The ASpace organization has hosted member forums since 2015, and some archivists have even held their own events, such as the Mid-Atlantic ArchivesSpace Interest Group's "skill share," http://histmed.collegeofphysicians. org/as-skill-share-2.

4. Figure based on “Who's Using ArchivesSpace?, http://archivesspace.org/community/whos-usingarchivesspace.

5. Dave Mayo and Kate Bowers, "The Devil's Shoehorn: A Case Study of EAD to ArchivesSpace Migration at a Large University," Code4Lib Journal 35 (2017), http://journal.code4lib.org/articles/12239.

6. Dallas Pillen, "Legacy EAD Import into ArchivesSpace," Bentley Historical Library Curation Team (blog), April 28, 2015, http://archival-integration.blogspot.com/2015/04/legacy-ead-import-intoarchivesspace.html.

7. Kate Dietrick, Laura Friedman-Shedlov, and Caitlin Marineau, "A Long and Twisted Road: The Journey from EAD to ArchivesSpace Implementation at the University of Minnesota," Journal of Archival Organization 13, nos. 3-4 (2016): 90-99, doi:10.1080/15332748.2018.1443462; Lisa Calahan and Kate Dietrick, "Setting the Stage and Keeping Sane: Implementing ArchivesSpace at the University of Minnesota," Journal of Archival Organization 13, nos. 3-4 (2016): 114-26, doi: 10.1080/15332748.2018.1443502.

8. Paromita Biswas and Elizabeth Skene, "From Silos to (Archives)Space: Moving Legacy Finding Aids Online as a Multi-Department Library Collaboration," The Reading Room: A Journal of Special Collections 1, no. 2 (2016), https://ubir.buffalo.edu/xmlui/handle/10477/60391.

9. Carol Ou, Katherine L. Rankin, and Cyndi Shein, "Repurposing ArchivesSpace Metadata for Original MARC Cataloging," Journal of Library Metadata 17, no. 1 (2017): 19-36, doi: 10.1080/19386389.2017.1285143. 
10. Kathryn Huida, Caitlin Marineau, and Amanda Wick, "Maximum Product, Even Less Process: Increasing Efficiencies in Archival Processing Using ArchivesSpace," Journal of Archival Organization 13, nos. 3-4 (2016): 100-113, doi: 10.1080/15332748.2018.1443549.

11. For an account of an Archon-to-ArchivesSpace migration, see Matthew Richardson and Bethany Scott, "Data in Flight: Preparing Legacy Finding Aids for Migration," Archival Outlook (January/ February 2018): 7, 18.

12. See resources at "Migration Tools \& Data Mapping," http://archivesspace.org/using-archivesspace/ migration-tools-and-data-mapping; and Mark Triggs, "Migrating to ArchivesSpace," Teaspoon Consulting, https://teaspoon-consulting.com/articles/migrating-to-archivesspace.html.

13. Maureen Callahan, “Migration, Step by Step," ArchivesSpace@Yale (blog), June 14, 2015, https:// campuspress.yale.edu/yalearchivesspace/2015/06/14/migration-step-by-step.

14. Eva Guggemos, "Pacific's Migration from Archivists' Toolkit > ArchivesSpace," CCD ACMWGArchivesSpace Pilot (blog), https://sites.google.com/site/ccdarchivesspace/pacifics-migration-fromat--as; Patrick Galligan, "From AT to ArchivesSpace, Part 1: Installation and Cleaning Data for Migration" and "Part 2: Migrations and Error Reporting," Bits \& Bytes: Newws from Rockefeller Archive Center's Digital Team (blog), December 12, 2014 and January 23, 2015, http://blog.rockarch .org/?p=1265 and 1289 .

15. Committee on Finding Aids, Inventories and Registers: A Handbook of Techniques and Examples (Chicago: Society of American Archivists, 1976), 29; David B. Gracy II, Archives \& Manuscripts: Arrangement and Description, Basic Manual Series (Chicago: Society of American Archivists, 1977), $29,32$.

16. For biographical information on David Gracy, see Kimberly D. Anderson, "Into the Breach: The Career of David B. Gracy II,” 2013, Iowa State University, http://works.bepress.com/kimberly_anderson/11; for the historical context of his 1977 manual, Anne Gilliland, "Professional, Institutional, and National Identities in Dialog: The Development of Descriptive Practices in the First Decade of the US National Archives," Information and Culture 49, no. 1 (2014): 54-56, doi: 10.7560/IC49104; on the Finding Aids Committee, see Thomas Elton Brown, "The Society of American Archivists Confronts the Computer," American Archivist 47, no. 4 (1984): 370-71, https://doi.org/10.17723/ aarc.47.4.av79522842886567.

17. This formulation of American archival history was articulated influentially in Richard Berner, Archival Theory and Practice in the United States: A Historical Analysis (Seattle: University of Washington Press, 1983) (esp. chapter 4 in this context); see also Rebecca Hirsch, "The Permanence of Provenance: The 'Two Traditions' and the American Archival Profession," Journal of Archival Organization 8, no. 1 (2010): 54-72, doi:10.1080/15332748.2010.486754 (the SAA Basic Manuals are discussed on 63-64, although Gracy's employer at that time is misidentified). For an account of the development of American finding aids that is sensitive to the two traditions thesis, see Ciaran B. Trace and Andrew Dillon, "The Evolution of the Finding Aid in the United States: From Physical to Digital Document Genre," Archival Science 12 (2012): 504-9, doi:10.1007/s10502-012-9190-5. Gilliland, "Professional, Institutional," also puts Gracy's manual in that context.

18. Steven L. Hensen, Archives, Personal Papers, and Manuscripts: A Cataloging Manual for Archival Repositories, Historical Societies, and Manuscript Libraries (Washington, DC: United States Government Printing Office, 1983); Nancy Sahli, MARC for Archives and Manuscripts: The AMC Format (Chicago: Society of American Archivists, 1985).

19. Gracy, Arrangement and Description, 32-33.

20. For a profession-level view of this sequence of standards refinement, see Susan E. Davis, "Descriptive Standards and the Archival Profession," Cataloging E Classification Quarterly 35, no. 4 (2003): 298-305, doi:10.1300/J104v35n03_02. The grant-funded project is described in Beth Bensman and Susan Potts McDonald, “The GAMMA Project: A Cooperative Cataloging Venture," Provenance 15, no. 1 (1997): 63-86, http://digitalcommons.kennesaw.edu/provenance/vol15/iss1/5.

21. Gracy, Arrangement and Description, ch. 4, "Special Record Material," 41-45, which also describes the creation and growth of the "printed collection" of GSU's Southern Labor Archives (41-42). 
22. The first year of the plan was FY 2015, and work began in the fall of 2014. Archival Associate Harold V. Hansen Jr. did the bulk of the editing work over the next three years and, in 2017, Matt Brooks, GSU Library's analyst programmer, lead, managed installation and data migration on the server; both worked with care and patience.

23. Variations due to individual processor and the flexibility permitted by EAD seem to be common in such migrations, which is more problematic when the quantity of finding aids is larger. See Mayo and Bowers, "Devil's Shoehorn," especially "Scale and Variety of Legacy Data," and Dietrick et al., "Long and Twisted Road," 93-94.

24. Over the years, GSU used $E A D$ Cookbook files with branding added, XSL files shared by generous colleagues at other institutions, and eventually the native CONTENTdm stylesheet to render EAD into HTML.

25. That is, instead of "English," the interface displayed "<language langcode="eng" $>$ English $<$ language >."

26. Via its OCLC record, the established form of the Asheville Carpenters name is now part of the EAC-CPF pilot program, Social Networks and Archival Context (SNAC), http://snaccooperative. org/ark:/99166/w62p3p0r.

27. For a range of pre-ASpace display options (for EAD and other formats), see Daniel A. Santamaria, "Designing Descriptive and Access Systems," Trends in Archives Practice Module 3, in Archival Arrangement and Description, ed. Christopher J. Prom and Thomas J. Frusciano (Chicago: Society of American Archivists, 2013): 172-80.

28. The other presentation mechanism built in to AT (not used at GSU) is its ability to assemble an EAD from a resource record, render it with a built-in stylesheet, and produce a PDF finding aid — again, a self-contained document.

29. On ignoring user needs, see Richard J. Cox, "Revisiting the Archival Finding Aid," Journal of Archival Organization 5, no. 4 (2007): 7-14, doi:10.1080/15332740802153245; on lack of appraisal information as a serious deficiency, Matthew Young Eidson, "Describing Anything that Walks," Journal of Archival Organization 1, no. 4 (2002): 17-20, doi:10.1300/J201v01n04_02; that finding aids "freeze" (quoting James B. Rhoads) both collections and their descriptions, Anne J. Gilliland, Conceptualizing 21't-Century Archives (Chicago: Society of American Archivists, 2014): 110-11, 126-27; on the voice of finding aids, Michelle Light and Tom Hyry, "Colophons and Annotations: New Directions for the Finding Aid," American Archivist 65, no. 2 (2002): 216-21.

30. Sharon Thibodeau, "Archival Inventory," in Encyclopedia of Archival Science, ed. Luciana Duranti and Patricia C. Franks (Lanham, Md.: Rowman \& Littlefield, 2015), 58-60.

31. Elizabeth H. Dow, "Encoded Archival Description as a Halfway Technology," Journal of Archival Organization 2, no. 3 (2009): 108-10, doi:10.1080/15332740903117701. For a review of concerns about serving users written fairly early in EAD's existence, see Lisa R. Coats, "Users of EAD Finding Aids: Who Are They and Are They Satisfied?," Journal of Archival Organization 7, no. 3 (2004): 25-39, doi:10.1300/J201v02n03_03.

32. Daniel V. Pitti, "Technology and the Transformation of Archival Description," Journal of Archival Organization 3, nos. 2-3 (2006): 18-21, doi:10.1300/J201v03n02_02.

33. Such a display did not originate with ASpace. For a review of the literature on finding aid usability and an explanation of the "single-level display" interface implemented at Brigham Young University, see J. Gordon Daines III and Cory L. Nimer, "Re-Imagining Archival Display: Creating UserFriendly Finding Aids," Journal of Archival Organization 9, no. 1 (2011): 2-31, http://dx.doi.org/1 0.1080/15332748.2011.574019.

34. T. R. Schellenberg, The Management of Archives (1965), reprint with a foreword by Jane Smith (Washington, DC: National Archives and Records Administration, 1988), 108. This statement is part of a caution to archivists not to control access to materials for the sake of their own "job security." 